\title{
On transition-zone water clouds
}

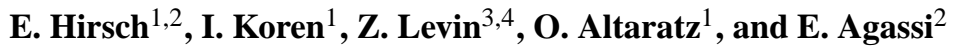 \\ ${ }^{1}$ Department of Earth and Planetary Sciences, Weizmann Institute of Science, Rehovot 76100, Israel \\ ${ }^{2}$ Department of Environmental Physics, Israel Institute for Biological Research, Nes Ziona, Israel \\ ${ }^{3}$ Department of Geophysical, Atmospheric and Planetary Sciences, Tel-Aviv University, Tel-Aviv, Israel \\ ${ }^{4}$ The Energy, Environment and Water Research Center (EEWRC), The Cyprus Institute, Nicosia, Cyprus
}

Correspondence to: I. Koren (ilan.koren@weizmann.ac.il)

Received: 26 November 2013 - Published in Atmos. Chem. Phys. Discuss.: 13 January 2014

Revised: 8 June 2014 - Accepted: 22 July 2014 - Published: 1 September 2014

\begin{abstract}
A recent field campaign was conducted to measure the properties of thin, warm convective clouds forming under conditions of weak updrafts. During the campaign, shortlived clouds (on the order of minutes) with droplets' effective radius of $1-2 \mu \mathrm{m}$ and low liquid water path $\left(\sim 500 \mathrm{mg} \mathrm{m}^{-2}\right)$ were measured. These low values are puzzling, since in most studies an effective radius of $4 \mu \mathrm{m}$ is reported to serve as the lower bound for clouds. A theoretical cloud model designed to resolve the droplet-activation process suggested conditions that favor the formation of such clouds. Here we show that these clouds, which mark the transition from haze to cloud, are highly sensitive to the magnitude of the initial perturbation that initiated them. We define these clouds as "transition-zone clouds". The existence of such clouds poses a key challenge for the analysis of atmospheric observations and models, since they "further smooth" the transition from dry aerosol through haze pockets to cumulus clouds.
\end{abstract}

\section{Introduction}

Although extensively studied for decades, there is no clear definition of a cloud. Clouds are often defined by thresholds that depend on the measurement technique and application, such as the cloud optical depth (COD) threshold when using remote-sensing tools, or the liquid water content (LWC) threshold in cases of in situ measurements and cloud numerical models. Such thresholds are not robust; they have been shown to misclassify the atmosphere and to introduce problems in analyses of both cloud and cloud-free regions (Koren et al., 2007; Charlson et al., 2007). On the microscale, the definition of a cloud droplet is more robust, since it is based on the clear physical discrimination between cloud and haze droplets, according to the Köhler theory (Kohler, 1936). A droplet that is large enough to grow spontaneously under environmental supersaturation is considered an activated cloud droplet. An inactivated droplet, which has not passed the thermodynamic barrier, is considered a haze droplet. Despite the absence of a clear definition for clouds, there is general agreement that a substantial number of a cloud's droplets are activated. For example, continental subarctic low-level clouds have been found to contain an average fraction of activation of $47 \%$ (with respect to number size distribution), with variations between 9 and $86 \%$ (Komppula et al., 2005).

There have been many studies on the temporal evolution of haze and cloud droplets (Mason and Chein, 1962; Mordy, 1959 and Reutter et al., 2009). The presence of these two thermodynamic states, controlled by the degree of supersaturation, suggests an interesting evolution of the droplets' sizedistribution function. Whereas haze is in a stable equilibrium, activated droplets are in an unstable equilibrium and their growth rate is inversely proportional to their radii. Such a diffusional growth rate dictates faster radial growth of small vs. bigger activated droplets. It has been shown that activated droplets in an ascending parcel reach a radius of more than $6 \mu \mathrm{m}$ in less than $100 \mathrm{~s}$, regardless of their initial size (Mordy, 1959). Therefore, the time during which the effective radius of the cloud droplet distribution is $1-3 \mu \mathrm{m}$ is very short, and the likelihood of a cloud to obtain such an effective radius is very small. However, the differences in drop growth rates become negligible as they grow. The growth rate of activated droplets with radius larger than $10 \mu \mathrm{m}$ depends mainly on the degree of supersaturation, rather than their size (Rogers, 1979). These properties create two droplet size gathering 
foci. One below the Köhler maxima that contains the haze particles, and the second one drifting toward the larger end of the spectrum of the growing activated droplets. Therefore, since the effective radius is biased toward the larger droplets, its value will usually be bigger than $1-3 \mu \mathrm{m}$. These considerations explain why a threshold radius of $4 \mu \mathrm{m}$ is often used as the lowest value that can represent a cloud (Kawamoto et al., 2001), and why an effective radius in the range of $1-3 \mu \mathrm{m}$ is considered transient, resulting in a small likelihood of capturing it for most cumulus clouds. These estimations agree well with observational records of effective radii of clouds. Extensive in situ measurements (Miles et al., 2000) of global marine and continental low-level stratiform clouds gave a mean effective radius $\left(r_{\text {eff }}\right)$ of $9.6 \pm 2.35$ and $5.4 \pm 2.05 \mu \mathrm{m}$, respectively. In addition, a nearly global survey of the effective radii in marine and continental shallow warm clouds (Han et al., 1994) indicated mean $r_{\text {eff }}$ values of 11.8 and $8.5 \mu \mathrm{m}$, respectively. Nevertheless, small $r_{\text {eff }}$ values, in the range of 3.5-5.5 $\mu \mathrm{m}$, have been reported for in situ measurements of continental boundary layer cumulus clouds (Han et al., 1995; Vogelmann et al., 2012). These values coincide well with the findings of Deng et al. (2009), who reported an average $r_{\mathrm{eff}}$ of $3.86 \mu \mathrm{m}$, with an average LWC of $0.16 \mathrm{~g} \mathrm{~m}^{-3}$, from in situ measurements of $\mathrm{Cu}$ clouds in Beijing. The smallest $r_{\text {eff }}$ values were reported by Reid et al. (1999), who studied the properties of warm convective clouds in Brazil by in situ measurements, and documented $r_{\text {eff }}$ readings of $2 \mu \mathrm{m}$ in a highly polluted environment. In addition, they provided a mathematical connection between the $r_{\text {eff }}$ and the LWC which could explain $70 \%$ of the variance in the measured data. Furthermore, in another study, a relationship between the liquid water path (LWP) and the $r_{\text {eff }}$ of a cloud was found (Liu et al., 2003), suggesting that a small $r_{\text {eff }}$ is positively correlated with small LWP.

During the eastern Mediterranean summer, it is typical to find stagnant atmospheric conditions, with a moist boundary layer and a near-neutral lapse rate that is bounded by an inversion layer. Since in many cases, the lifting condensation level (LCL) is located above the inversion layer, standard forecasting tools predict no cloud formation on these days.

In this study, we focus on the very small end of the size distribution of convective clouds. During a recent field campaign (see next section for further details), we measured many short-lived $\mathrm{Cu}$ clouds (see an example in Fig. 1) that were characterized by very small $r_{\text {eff }}$ values. Our study raises several questions: are these clouds? According to which definition can we identify them as clouds (remote sensing, modeling, microphysical)? Using theoretical cloud equations together with observations, we study the properties of this unique subset of clouds.

\section{Methods}

A field campaign was conducted during the summer (JuneAugust) of 2011 in Israel, focusing on the microphysical and optical properties of thin, warm convective clouds. The measurement site was in Nes Ziona, which is located approximately $10 \mathrm{~km}$ away from the coast. The cloud properties were retrieved using a novel ground-based hyperspectral technique (Hirsch et al., 2012) which was developed to retrieve the optical (COD) and microphysical $\left(r_{\text {eff }}\right.$, LWP) properties of thin, warm clouds. It relies on three elements: detailed radiative-transfer calculations in the longwave-IR (infrared) regime, signal enhancement by subtraction of a clear sky reference, and a spectral matching method that exploits fine spectral differences between water droplets of different radii. The sensors were pointed to the zenith and the measurements were conducted at a rate of $0.5 \mathrm{~Hz}$, thus the COD, $r_{\text {eff }}$ and LWP were derived every $2 \mathrm{~s}$. Since the retrieval is based on spectral analysis, its accuracy is not constant for all values of $r_{\text {eff }}$. However, the retrieval is at its highest sensitivity for thin clouds, and the error is estimated to be $\pm 0.5 \mu \mathrm{m}$ for $r_{\text {eff }} \approx 2 \mu \mathrm{m}$ and for LWP $<10 \mathrm{~g} \mathrm{~m}^{-2}$ (see Hirsch et al., 2012 for further details).

Complementary measurements of the atmospheric profile and cloud-base height were conducted by the Israel Meteorological Service (IMS) at the Beit Dagan station, which is located $10 \mathrm{~km}$ north of the cloud-measurement system, at a similar distance from the coast. Thus, the influence of the sea breeze on the atmospheric conditions at both sites is expected to be similar. The cloud-base height was measured by a ceilometer, and the atmospheric conditions were measured twice a day by a radiosonde (at 00:00 and 12:00 UTC - universal time coordinated). The data were downloaded from the University of Wyoming website (Atmospheric sounding: http://weather.uwyo.edu/upperair/sounding.html). The radiosonde provides information on temperature, pressure, humidity, and horizontal wind speed profiles from the surface to the end of the troposphere. As explained later, the daily 12:00 UTC atmospheric profiles were used as an input data for the theoretical cloud model and for calculating the expected cloud-base height (based on LCL). Those values were compared to the measured cloud-base height at the same geographical location, at Beit Dagan.

To examine the atmospheric conditions under which such clouds can form, a theoretical cloud model was developed. We used the basic cloud physics equations to investigate airparcel evolution under weak updraft conditions, below a thermal inversion (see Appendix A for a comprehensive description of the parcel model). There are parcel models that use conserved thermodynamic parameters such as potential temperature or equivalent potential temperature (see for example Berg and Stull, 2004). However, the purpose of our model was to resolve the parcel motion and to enable analyzing in detail the uptake of water vapor by haze droplets and of the droplet activation process. The model solves the first law 


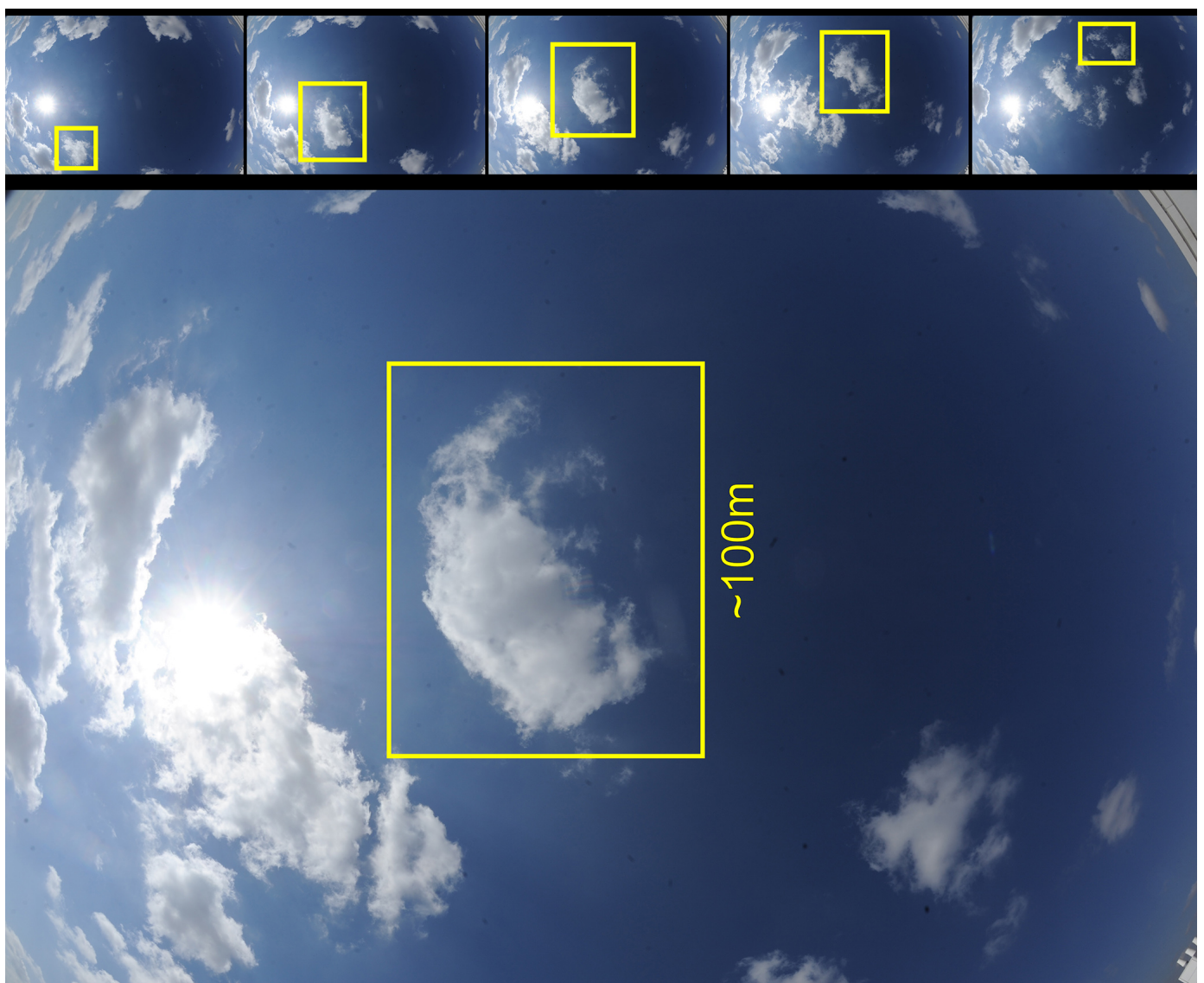

Figure 1. Images taken during a field campaign on 30 June 2011 at 15:52-15:56 LT. Top: sequential (1 min time lag) images of the complete lifetime of a single short-lived cloud. The camera was pointed at the zenith and the diagonal field of view is $180^{\circ}$. The yellow rectangles mark the position of the cloud. Bottom: enlargement of one of the images.

of thermodynamics directly. As detailed in Appendix A, the cloud model accounts for the effect of entrainment only on the momentum. However, under the specific conditions of relatively weak updrafts, which serve as the "entrainment engine", such representation provides a reasonable approximation. Moreover, the coupling between the model's equations imposes interaction of the entrainment process with all other processes.

The droplet $r_{\text {eff }}$ and supersaturation within the parcel, as well as the cloud's updraft and LWC, were calculated for a range of initial conditions. The 24 dry aerosol size distributions used in the model were measured in situ in Europe and in the Mediterranean (Asmi et al., 2011), and the aerosols were assumed to be ammonium sulfate.

\section{Results}

Here we present a detailed case study of 1 day in the field campaign (30 June 2011; see the tephigram in Appendix B, Fig. B1). Analysis of the cloud measurements from that day revealed many short-lived clouds with uncommonly small $r_{\text {eff. }}$ An example of one specific cloud is presented in Fig. 1. The cloud appears ordinary to the naked eye, and it has a short lifetime of only $6 \mathrm{~min}$. Use of the retrieval method revealed the COD, LWP and $r_{\text {eff }}$ as the cloud passed above the sensors in the zenith. The temporal average $r_{\text {eff }}$ of the cloud (as it passed in the zenith) was $1.24 \mu \mathrm{m}$ (with standard deviation of $\sigma=0.2 \mu \mathrm{m}$ ), the average LWP was $0.13 \mathrm{~g} \mathrm{~m}^{-2}$ (with 0.01 and $0.37 \mathrm{~g}^{-2}$ as the 10th and 90th percentiles respectively), and the average COD at $550 \mathrm{~nm}$ was 9.15 (with 0.66 and 30.3 as the 10th and 90th percentiles respectively). The data collected on this day showed many more clouds with similar characteristics. Most of the $r_{\text {eff }}$ readings at noontime of that day were smaller than $2 \mu \mathrm{m}$ (Fig. 2) and the clouds had a relatively short lifetime (several minutes at most).

Based on the sounding data from the Beit Dagan meteorological station measured on 30 June 2011 at 12:00 UTC (15:00 LT - local time), we simulated the formation of thin warm clouds on that day. The dry aerosol number size distribution that was used is based on measured aerosol size spectra from the island of Crete, and the diameters can be represented as a sum of two log-normal distributions centered at 86 and $189 \mathrm{~nm}$ (see full description in Asmi et al., 


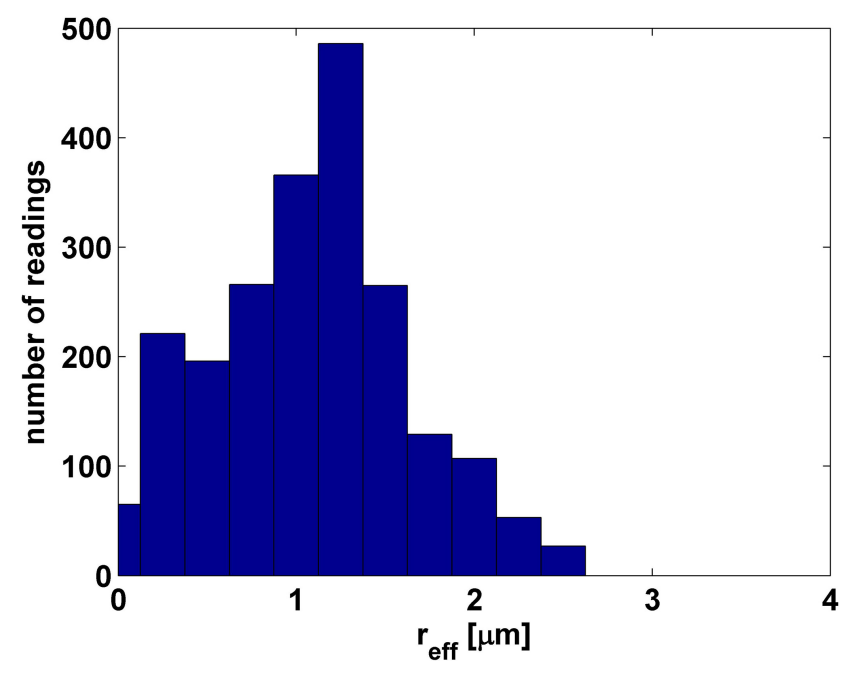

Figure 2. A histogram of $r_{\mathrm{eff}}$ readings from 14:00 to 16:00 LT on 30 June 2011. Most of the $r_{\text {eff }}$ readings are below $2 \mu \mathrm{m}$. Data were measured at a rate of $0.5 \mathrm{~Hz}$.

2011, station FKL). A wide range of RH (relative humidity) perturbations and initial vertical locations were used (presented in more detail further on). Figure 3 shows an example of one simulation of the formation of a small, warm cloud. To initiate the cloud formation we used a RH perturbation of $11 \%$ above ambient RH (68\%), at a height of $550 \mathrm{~m}$. The initial updraft of the parcel was set to zero, and its temperature was equal to the ambient temperature at that level $\left(20.1^{\circ} \mathrm{C}\right)$. Examination of Fig. 3 reveals that the parcel rose $\sim 475 \mathrm{~m}$ and reached a low supersaturation of $\sim 0.2 \%$, along with a LWC of $2.15 \mathrm{mg} \mathrm{m}^{-3}$. The maximal $r_{\text {eff }}$ of the droplets was $1.95 \mu \mathrm{m}$, while the parcel drifted up with a weak updraft (average of $86 \mathrm{~cm} \mathrm{~s}^{-1}$ ), reaching a maximal value of $128 \mathrm{~cm} \mathrm{~s}^{-1}$ for a very short time (see Fig. 3). It is interesting to note the time lag between the maximal updraft and maximal LWC. At the stage of maximal updraft, the parcel contains only haze droplets, none of its droplets are activated and it is subvisual to the naked eye. When the parcel reaches its maximal LWC (and supersaturation), the updraft is completely exhausted, it turns into a downdraft and the cloud is already in the dissipation stage.

The dependency of the cloud's properties on the initial $\mathrm{RH}$ of the parcel was examined and the results are presented in Fig. 4. The ambient RH was $68 \%$ and the perturbations ranged between 7 and $17 \%$. Every point in the figure represents the results of a complete simulation, similar to the one presented in Fig. 3, using the same dry aerosol size distribution (based on measurements from Crete; Asmi et al., 2011). The maximal $r_{\text {eff }}$ (blue), maximal RH (red), and maximal LWC (black) of the forming clouds were plotted against the initial RH of the parcel. In addition, the fraction of activated droplets (in terms of number size distribution) is plotted against the initial RH (magenta). To emphasize the dependency of the maximal $r_{\text {eff }}$ on initial $\mathrm{RH}$, we

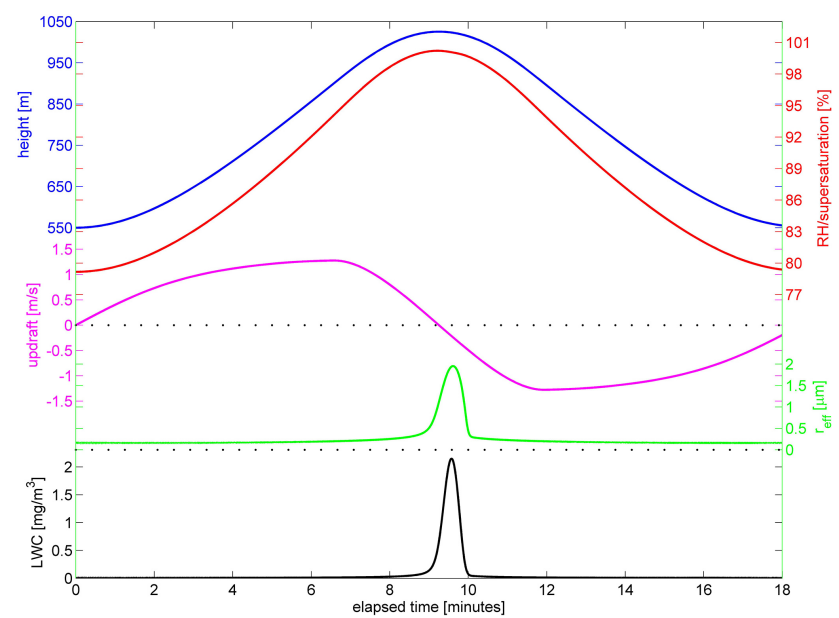

Figure 3. Temporal evolution of an air parcel. Vertical position (blue), RH and supersaturation (red), updraft (magenta), $r_{\text {eff }}$ (green), and LWC (black).

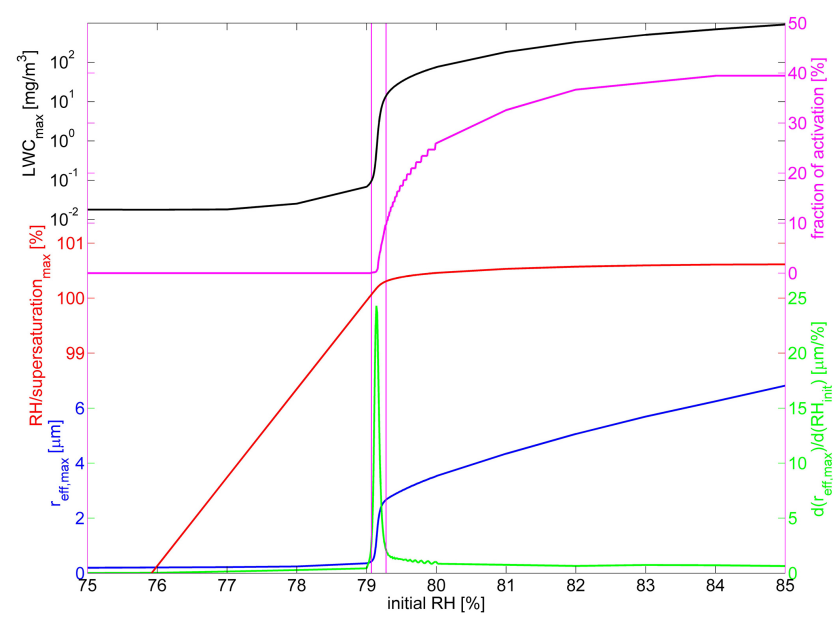

Figure 4. The maximal $r_{\text {eff }}$ (blue), maximal RH (red), maximal LWC (black), and fraction of activation (in terms of number size distribution, magenta) of the forming clouds vs. the initial RH of the parcel. The green line is the derivative of the maximal $r_{\mathrm{eff}}$ with respect to the initial RH of the parcel. Transition-zone clouds are defined within the vertical magenta lines (see text for further explanation).

plotted the derivative of the blue line $\left(r_{\text {eff,max }}\right)$ against $\mathrm{RH}_{\text {init }}$ $\left(d\left(r_{\text {eff,max }}\right) / d\left(\mathrm{RH}_{\text {init }}\right)\right.$, in green $)$. We defined the cases with $d\left(r_{\text {eff,max }}\right) / d\left(\mathrm{RH}_{\text {init }}\right)>2 \mu \mathrm{m} \%^{-1}$ as "transition-zone" clouds (marked with vertical magenta lines). The clear and narrow transition zone seen in all of the graphs ( $r_{\text {eff }}, \mathrm{RH}$ and LWC) implies that these clouds are highly sensitive to the initial conditions of the parcel. Furthermore, it reinforces the common assumption of a minimal $r_{\text {eff }}$ of $4 \mu \mathrm{m}$ for clouds, located well beyond the transition zone.

Although the marked region appears small, it does not necessarily represent the likelihood of such conditions in nature; 
in fact, it represents a wide range of possible values. The range of the maximal $r_{\text {eff }}$ is from 0.43 to $2.67 \mu \mathrm{m}$, while the range of the maximal LWC is between 0.1 and $14.1 \mathrm{mg} \mathrm{m}^{-3}$. In addition, maximal supersaturation ranges between 0.07 and $0.31 \%$, whereas the average updraft is approximately constant at $0.86 \mathrm{~m} \mathrm{~s}^{-1}$. It is also interesting to note that the maximal fraction of activation can be in some clouds lower than $10 \%$ (in terms of number size distribution), which is the lower limit that can be measured in cumulus clouds (Komppula et al., 2005).

Furthermore, it is possible to define a criterion for the cloud's lifetime. For every simulated cloud, we defined its lifetime as the period during which the $r_{\text {eff }}$ exceeds $0.5 \mu \mathrm{m}$. This threshold was chosen since it represents the beginning of the droplet activation process in clouds. For the clouds that appear in Fig. 4, when the maximal $r_{\text {eff }}$ reaches $0.5 \mu \mathrm{m}$, the fraction of activation (in terms of number size distribution) is $0.13 \%$. Using this definition, the range of possible lifetimes spans up to $1.4 \mathrm{~min}$.

Further examination of the model results, for a range of different initial vertical locations of the parcel and initial RH values, revealed a range of possible values for the microphysical properties and lifetimes of the formed clouds. In every panel in Fig. 5, the temperature (blue) and RH (red) profiles are plotted along with the ceilometer measurement of cloud-base height (horizontal blue line) and the theoretical LCLs (horizontal cyan and magenta lines). As detailed in Appendix A, one of the LCL calculations was based on a ground-level ascending parcel and the other on a parcel with average properties of the lowest $500 \mathrm{~m}$. First, we note that the measured cloud base is $\sim 500 \mathrm{~m}$ below the LCL (both the cloud base and atmospheric profile for estimating LCL were measured in Beit Dagan). According to the cloud model results, only parcels that initiated at altitudes between 250 and $750 \mathrm{~m}$ formed a cloud-base height that is comparable with the actual measured one. Therefore, only those parcels' results are presented. In Fig. 5a, the lower symbol of every pair of symbols represents both the initial height of the parcel and the size of the smallest RH perturbation that created a cloud (determined by a threshold of RH > 100\%). The higher symbol of every pair represents the simulated cloud-base height. It can be noticed that all the parcels that originated between 250 and $750 \mathrm{~m}$ created clouds with similar base heights that are comparable with the measured value.

Figure $5 \mathrm{~b}-\mathrm{f}$ present the possible values of maximal $r_{\mathrm{eff}}$, maximal LWC, maximal supersaturation, lifetime, and average updraft, respectively. The colored region corresponds to the value of the simulated parameter. The position of the colored region on the graph represents the initial height of the parcel and the magnitude of the RH perturbation; i.e., the difference between the lower colored region and the red line represents the perturbation in the $\mathrm{RH}$.

By analyzing the results presented in Fig. 5 and following the definition of transition-zone clouds, it is possible to calculate the possible supersaturation, LWC and $r_{\text {eff }}$ values of those clouds, while considering different heights from which the parcel might have started to ascend. The maximal $r_{\mathrm{eff}}$ varies between 0.41 and $2.69 \mu \mathrm{m}$, while the maximal LWC ranges between 0.09 and $16.8 \mathrm{mg} \mathrm{m}^{-3}$. The maximal supersaturation varies between 0.05 and $0.33 \%$ and the average updraft ranges between 0.62 and $1.15 \mathrm{~m} \mathrm{~s}^{-1}$. When considering the possible initial heights of the parcel, the lifetime of the transition-zone clouds may reach $13.5 \mathrm{~min}$, but it is often much shorter.

How sensitive are these results to the aerosol model? To study the effect of dry aerosol size distribution on the properties of the forming clouds, we used 24 types of dry aerosol size distributions that had been measured in situ in Europe and the Mediterranean region (Asmi et al., 2011). Figure 6 demonstrates that the phenomenon of transition-zone clouds is independent of the dry aerosol size distribution, although the microphysical properties (LWC, supersaturation, $r_{\text {eff }}$ ) of the forming clouds are affected. Fig. 6 presents a group of curves representing the results of 3192 different simulations for 24 types of dry aerosol size distributions (every distribution with 133 different initial RH perturbations). The maximal $r_{\text {eff }}$ of the droplets is presented vs. the maximal LWC in the cloud. All parcels were initiated at a height of $550 \mathrm{~m}$, while every point on the curves represents a full simulation, similar to the one presented in Fig. 3, for a different initial dry aerosol size distribution and different initial RH perturbations. An examination of the curves shows the regime in this phase space as dominated by "transition-zone" clouds. This regime is determined based on the presented criterion for recognizing the zone of sharp change in cloud properties as a function of the initial RH perturbation for similar dry aerosol distribution simulations (see explanation of Fig. 4). In a subsaturated air parcel, haze develops with a submicron $r_{\text {eff }}$ (shaded yellow region). However, an initial perturbation with relatively high RH compared to the environment (shaded blue region) can produce more developed clouds that are characterized by larger $r_{\text {eff }}$ and higher LWC. In the intermediate zone (shaded magenta region) transition-zone clouds are formed, namely clouds that are transitional between haze and $\mathrm{Cu}$ clouds. They are, by definition, highly sensitive to the initial RH perturbation. When considering the wide range of possible dry aerosol size distributions, the maximal $r_{\text {eff }}$ may vary between 1.5 and $6 \mu \mathrm{m}$, while the maximal $\mathrm{LWC}$ ranges between 0.01 and $73 \mathrm{mg} \mathrm{m}^{-3}$. The supersaturation can be as high as $0.6 \%$, while the average updraft is almost unaffected by the aerosol size distribution (range of $0.85-0.87 \mathrm{~m} \mathrm{~s}^{-1}$ ).

Obviously, the occurrence of transition-zone clouds is not restricted to the eastern Mediterranean region. Similar atmospheric conditions are quite common during the summer in other locations around the globe (specifically coastal areas along the subtropical belt), in which a persistent synopticscale subsidence exists. In such places, it is common to see small (on the scale of $100 \mathrm{~m}$ ) cumulus clouds that form and dissipate within a few minutes. 

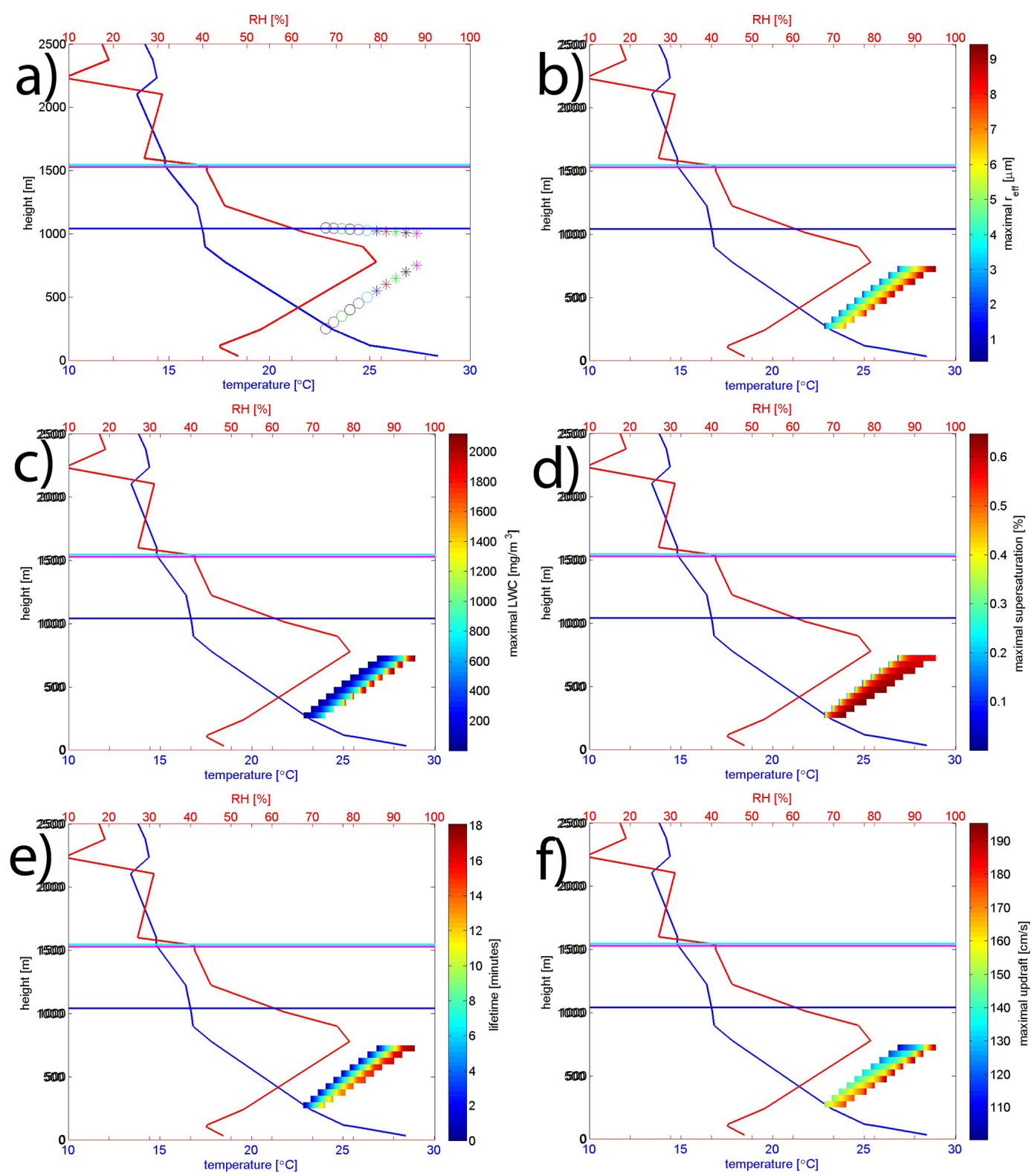

Figure 5. Theoretical cloud model results for a range of possible initial heights and RH perturbations for the atmospheric profile of 30 June 2011, 12:00 UTC. (a) The lower symbol of every pair of symbols represents both the initial height of the parcel and the size of the smallest RH perturbation that created a cloud (determined as RH> $100 \%$ ). The higher symbol of every pair represents the simulated cloud-base height. Note that all of the simulated parcels (initial heights $250-750 \mathrm{~m}$ ) resulted in a cloud base at the measured value (horizontal blue line). (b) Possible values of the maximal $r_{\text {eff }}$ for different initial heights and different perturbations. The colored region corresponds to the value of the simulated maximal $r_{\text {eff }}$. The position of the colored region on the graph represents the initial height of the parcel and the magnitude of the RH perturbation. (c-f) same as (b) but for maximal LWC, maximal supersaturation, lifetime, and average updraft, respectively.

\section{Summary and discussion}

In this study, we focused on a cloud regime that is usually overlooked. Observational evidence for warm clouds with small $r_{\text {eff }}$, small LWP, and a short lifetime were found during a field campaign. These observations initiated a detailed analysis using a bin microphysics cloud model to study the microphysical properties of small, short-lived convective clouds under a weak updrafts regime in a humid boundary layer bounded by a thermal inversion. The model predicts that, under such conditions, a special subset of clouds with unique microphysical properties can form. Such clouds are defined here as transition-zone clouds because their thermodynamic state is in the transition between haze and cumulus clouds. They are highly sensitive to the initial perturbation, and they are characterized by a $r_{\text {eff }}<\sim 3 \mu \mathrm{m}$, which is conventionally 


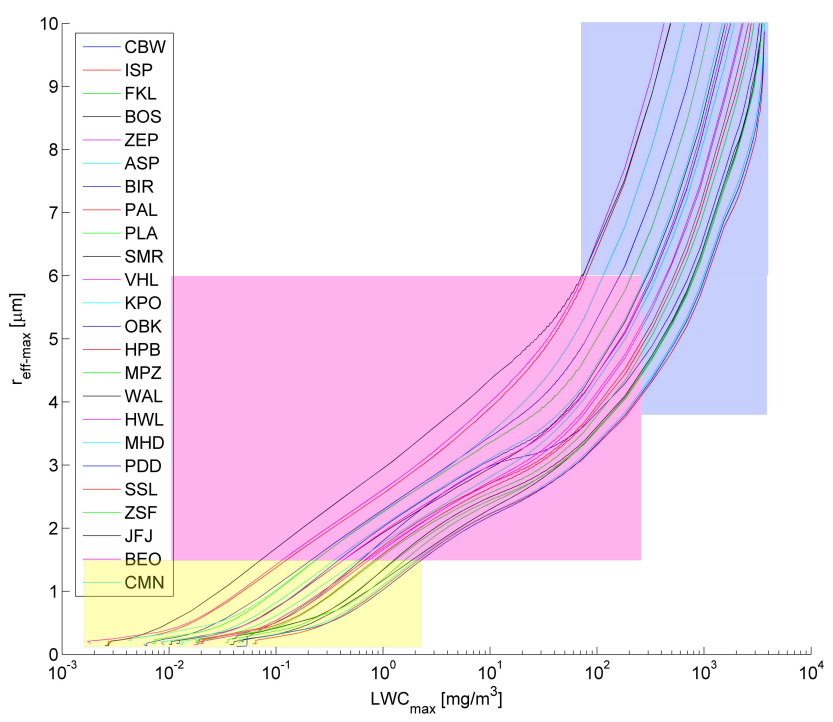

Figure 6. The maximal effective radius $\left(r_{\text {eff }- \text { max }}\right)$ vs. the maximal liquid water content $\left(\mathrm{LWC}_{\max }\right)$ in the cloud for different dry aerosol size distributions (Asmi et al., 2011) and different initial relative humidity perturbations. Each line represents a different dry aerosol size distribution. The labels follow the names given by Asmi et al. (2011). The different shaded regions represent conditions of haze (subsaturation, yellow), transition-zone clouds (magenta), and more developed $\mathrm{Cu}$ clouds (blue).

considered below the threshold of cumulus clouds. Such clouds contain a relatively low $\mathrm{LWC}\left(<17 \mathrm{mg} \mathrm{m}^{-3}\right)$, and have a small COD. In addition, these clouds reach their maximal LWC when their driving updraft has already dissipated. There is a possibility that the atmospheric conditions at the measurement site, (at Nes Ziona) where the clouds characteristics were measured, were different from the atmospheric profiles measured at the Beit Dagan station, but due to the similar distances of both stations from the seashore it is not plausible.

Because of their temporal and spatial properties, such clouds are likely to escape the scientific "cloud radar". Small, short-lived clouds form a collective suite of challenges to study. Their physical properties fall below most of the sampling rate and sensitivity limits of in situ measurement instruments, and are smaller than the spatial resolution of most climate-oriented remote-sensing sensors. Moreover, most of the RH measurement techniques are limited to a lower supersaturation of $0.2 \%$ (Snider et al., 2003); and measurements of low supersaturation are difficult to perform and are usually highly inaccurate (Rose et al., 2008). It is therefore quite hard to characterize these clouds.
This study raises several interesting and important issues regarding the way in which clouds are defined. Our results can be generalized, suggesting that there are convective clouds with maximal size in the range of a few hundred meters or less, which form below an inversion layer, characterized by low supersaturation values.

It has already been noted that the region between clouds within a cloud field (also known as the clouds' twilight zone; Koren et al., 2007) is characterized by unique optical properties, and that the commonly used discrimination between clear and cloudy skies might lead to substantial errors in estimating radiative forcing (Charlson et al., 2007). In this paper, we explore the range of small clouds that lie between haze and conventional, more developed cumulus clouds, and introduce the transition-zone cloud. Although these clouds seem to exist for only a relatively small range of initial conditions, they are expected to be quite common, since they form in common environmental conditions. Moreover, a link is expected between the clouds' size and frequency of occurrence (Koren et al., 2008; Wood and Field, 2011; Zhao and Girolamo, 2007). As these clouds occupy the small end of the $\mathrm{Cu}$ cloud size distribution, their number is the highest. Since previous studies reported cases where small clouds contributed $\sim 50 \%$ of the reflectance (Koren et al., 2008), these findings suggest that at some environmental conditions the subset of transition-zone clouds has an important radiative forcing effect which is currently either not considered or wrongly attributed to aerosols.

Furthermore, these clouds might better explain the unique optical properties of the clouds' twilight zone. Our findings suggest that weight should be given to theoretical studies, as well as to the development of instruments and measuring techniques that will enable us to advance our knowledge of this important and understudied subset of clouds. 


\section{Appendix A: The cloud model}

Unlike many parcel models in which the parcel's updraft is prescribed, in our theoretical analysis, we developed an air parcel model that is tuned to resolve the initiation of small buoyant air pockets that form due to weak perturbations in temperature or humidity. In order to account for the delicate processes that take place in the transition from haze to activated cloud droplets, the model solves the thermodynamic equations from first principles.

The core physics is based on the following equations that combine the vertical motion of a rising moist air parcel with the diffusional growth of humidified aerosols and water droplets within the parcel. All air parcel models implement some form of the first law of thermodynamics, usually as follows (Wallace and Hobbs, 2006):

$\mathrm{d} T=\frac{1}{c_{p}}\left(\mathrm{~d} q+R T \frac{\mathrm{d} p}{p}\right)$.

(See Table A1 for a complete description of the symbols.)

Equation (A1) describes changes in the parcel temperature $(\mathrm{d} T) ; \mathrm{d} T$ increases with the release of latent heat that occurs as water vapor condenses $(\mathrm{d} q)$ and cools as a result of the expansion of the parcel $(R T \mathrm{~d} p / p)$. The latent heat released by inactivated haze droplets is incorporated into the model by means of a detailed scheme that treats the growth of humidified aerosols. The term $\mathrm{d} q$ is calculated by multiplying the change in mass of all the droplets (haze droplets and activated cloud droplets) with the latent heat. Namely

$\mathrm{d} q=L_{\mathrm{e}} \sum_{\text {all droplets }} \mathrm{d} m$

where $\mathrm{d} m(r)=4 / 3 \pi \rho\left(r^{3}-(r-\mathrm{d} r)^{3}\right)$, and $L_{\mathrm{e}}=10^{3} \times$ $\left(2500.8-2.36 T+0.0016 T^{2}-0.00006 T^{3}\right)$ (for $T$ in ${ }^{\circ} \mathrm{C}$; Rogers, 1979). In order to simplify the model, we neglected the effect of water vapor and liquid water on the specific heat $\left(c_{p}\right)$ and used a constant value of dry air (Pruppacher and Klett, 1988).

The growth rate of every haze or cloud droplet is determined by a diffusion equation that depends on the difference between the ambient relative humidity (or supersaturation) in the air parcel $\left(s_{\mathrm{v}, \mathrm{w}}\right)$ and the relative humidity adjacent to the droplet (Kohler, 1936). The growth rate also depends on the heat conductivity and diffusion coefficients of the condensing water droplets. These relationships are described by Pruppacher and Klett (1998) as follows:

$$
\begin{aligned}
r \frac{\mathrm{d} r}{\mathrm{~d} t} & =\frac{D_{\mathrm{v}}^{*} M_{\mathrm{w}} \mathrm{e}_{\mathrm{sat}, \mathrm{w}}\left(T_{\infty}\right)}{\rho_{\mathrm{s}}^{\prime \prime} R T}\left(1+s_{\mathrm{v}, \mathrm{w}}-\frac{1}{1+\delta} \exp \left[\frac{L_{\mathrm{e}} M_{\mathrm{w}}}{R T}\left(\frac{\delta}{1+\delta}\right)\right.\right. \\
& \left.\left.+\frac{2 M_{\mathrm{w}} \sigma_{\mathrm{s} / \mathrm{a}}}{R T(1+\delta) \rho_{\mathrm{w}} r}-\frac{v \Phi_{\mathrm{s}} \varepsilon_{\mathrm{m}} M_{\mathrm{w}} \rho_{\mathrm{N}} r_{\mathrm{N}}^{3}}{M_{\mathrm{s}} \rho_{\mathrm{w}}\left(r^{3}-r_{\mathrm{N}}^{3}\right)}\right]\right) .
\end{aligned}
$$

The rate of change of the supersaturation depends on two competing processes. The supersaturation increases when the air parcel cools as it ascends and decreases when vapor is depleted by the condensational growth of the haze and cloud droplets (Lee and Pruppacher, 1977):

$$
\frac{\mathrm{d} s_{\mathrm{v}, \mathrm{w}}}{\mathrm{d} t}=\frac{p}{\varepsilon \mathrm{e}_{\mathrm{sat}, \mathrm{w}}} \frac{\mathrm{d} w_{\mathrm{v}}}{\mathrm{d} t}-\left(1+s_{\mathrm{V}, \mathrm{w}}\right)\left(\frac{\varepsilon L_{\mathrm{e}}}{R_{\mathrm{a}} T^{2}} \frac{\mathrm{d} T}{\mathrm{~d} t}+\frac{g}{R_{\mathrm{a}} T} U\right) .
$$

The second term on the right-hand side of the equation represents the effect of the adiabatic cooling on the saturation vapor pressure, while the third term represents the effect of the expansion of the parcel on the vapor pressure.

The latter equation is derived under the assumptions that the partial pressure of the dry air equals the pressure of the parcel, the density of the parcel equals the density of dry air, and that $\mathrm{d} p / \mathrm{d} t \approx-g \rho U$.

The rate of change in the updraft of the parcel $(U)$ is derived from momentum considerations (Lee and Pruppacher, 1977). A positive thermal contrast between the parcel and the environment accelerates the parcel, while the drag force resulting from the condensing water decelerates the parcel. The last term represents the effect of the entrained air on the updraft. Since all the model's equations are coupled and the updrafts are small, this formalism represents reasonable treatment of the effect of the entrained air on the parcel motion (Pruppacher and Klett, 1998):

$$
\frac{\mathrm{d} U}{\mathrm{~d} t}=\frac{g}{1+\gamma}\left(\frac{T_{\mathrm{v}}-T_{\mathrm{v}}^{\prime}}{T_{\mathrm{v}}^{\prime}}-W_{\mathrm{L}}\right)-\mu_{\mathrm{J}} U^{2} .
$$

The inputs to the model are the atmospheric profiles (temperature, relative humidity and pressure), the initial conditions of the parcel (vertical position, initial relative humidity, initial temperature and initial updraft) and the size distribution and chemical composition of the dry aerosol. The model calculates the temporal evolution of the vertical position, temperature, relative humidity, updraft and the size distribution of the growing water droplets of the parcel. The cloud-base height was determined from the model results for a relative humidity level of $100 \%$. Since the model uses measured atmospheric profiles, the pressure is determined from the vertical position of the parcel at every time step.

In our model, the input data for the dry aerosol size distribution are based on number size distributions measured in Europe (Asmi et al., 2011). The distribution is represented by a discrete 250-bin parameterization sampled on a logarithmic scale. Because the influence of the size distribution of the aerosols on the cloud's properties greatly exceeds that of the chemistry of the aerosols (Reutter et al., 2009 and Dusek et al., 2006), we assumed that all of the aerosols are ammonium sulfate; this assumption also allowed us to simplify the model. Furthermore, because the deliquescent relative humidity of ammonium sulfate is approximately $80 \%$ (Brooks et al., 2002), we can assume that aerosols take up water vapor by diffusion in the very early stages of air parcel 
Table A1. List of symbols.

\begin{tabular}{|c|c|c|}
\hline Symbol & Quantity & Units \\
\hline$T$ & Air temperature inside the parcel & $\mathrm{K}$ \\
\hline$q$ & Latent heat release & $\mathrm{J} \mathrm{kg}^{-1}$ \\
\hline$R$ & Gas constant for 1 mole of ideal gas & $\mathrm{J}$ mole $^{-1} \mathrm{~K}^{-1}$ \\
\hline$p$ & Pressure & $\mathrm{J} \mathrm{m}^{-3}$ \\
\hline$r$ & Droplet radius & $\mathrm{m}$ \\
\hline$D_{\mathrm{y}}^{*}$ & Modified diffusivity of water vapor in air & $\mathrm{m}^{2} \mathrm{~s}^{-1}$ \\
\hline$M_{\mathrm{W}}$ & Molecular weight of water & mole $^{-1}$ \\
\hline$M_{\mathrm{S}}$ & Molecular weight of salt & mole $^{-1}$ \\
\hline$e_{\mathrm{sat}, \mathrm{w}}$ & Saturation vapor pressure over a plane water surface & $\mathrm{J} \mathrm{m}^{-3}$ \\
\hline$\rho_{\mathrm{S}}^{\prime \prime}$ & Density of aqueous salt solution & $\mathrm{kg} \mathrm{m}^{-3}$ \\
\hline$s_{\mathrm{V}, \mathrm{w}}$ & Supersaturation of water vapor with respect to a plane water surface & unitless \\
\hline$\delta$ & $\frac{T_{\mathrm{a}}}{T_{\infty}}-1$ & unitless \\
\hline$L_{\mathrm{e}}$ & $\begin{array}{l}I_{\infty} \\
\text { Latent heat of evaporation of pure water }\end{array}$ & $\mathrm{J} \mathrm{kg}^{-1}$ \\
\hline$\sigma_{\mathrm{s} / \mathrm{a}}$ & Surface tension of an aqueous solution drop against air & $\mathrm{J} \mathrm{m}^{-2}$ \\
\hline$\rho_{\mathrm{W}}$ & Density of water & $\mathrm{kg} \mathrm{m}^{-3}$ \\
\hline$v$ & Number of ions into which a salt molecule dissociates in water & unitless \\
\hline$\Phi_{\mathrm{S}}$ & Osmotic coefficient & unitless \\
\hline$\rho_{\mathrm{N}}$ & Density of dry aerosol & $\mathrm{kg} \mathrm{m}^{-3}$ \\
\hline$r_{\mathrm{N}}$ & Radius of dry aerosol & $\mathrm{m}$ \\
\hline$\varepsilon$ & Molecular weight ratio of $\mathrm{H}_{2} \mathrm{O}$ to dry air $(=0.622)$ & unitless \\
\hline$w_{\mathrm{v}}$ & Mixing ratio of water vapor & $\mathrm{g} \mathrm{g}^{-1}$ \\
\hline$R_{\mathrm{a}}$ & Gas constant for $1 \mathrm{~g}$ of dry air & $\mathrm{J} \mathrm{kg}^{-1} \mathrm{~K}^{-1}$ \\
\hline$g$ & Acceleration of gravity & $\mathrm{m} \mathrm{s}^{-2}$ \\
\hline$U$ & Vertical velocity of air parcel & $\mathrm{m} \mathrm{s}^{-1}$ \\
\hline$\gamma$ & 0.5 correction for induced mass acceleration (Pruppacher and Klett, 1998) & unitless \\
\hline$T_{\mathrm{V}}$ & Virtual temperature of air parcel & $\mathrm{K}$ \\
\hline$T_{v}^{\prime}$ & Virtual temperature of environment & $\mathrm{K}$ \\
\hline$W_{\mathrm{L}}$ & Liquid water mixing ratio in the air parcel & $\mathrm{g}_{\text {water }} \mathrm{g}_{\text {air }}^{-1}$ \\
\hline$\mu_{\mathrm{J}}$ & Entrainment rate for a convective plume & $\mathrm{m}^{-1}$ \\
\hline$\varepsilon_{\mathrm{m}}$ & Mass fraction of water soluble substance in mixed aerosol particle & unitless \\
\hline$R$ & The universal gas constant & $\mathrm{J} \mathrm{K}^{-1} \mathrm{~mole}^{-1}$ \\
\hline
\end{tabular}

movement. To increase the accuracy of the model, we used a fine temporal resolution of $2.5 \mathrm{~ms}$.

In addition we used measurements obtained by the Israeli Meteorological Service (IMS). The IMS station at Beit Dagan is located $10 \mathrm{~km}$ east of the Mediterranean shore and measures the atmospheric profile on a daily basis by releasing a radiosonde at 12:00 UTC (15:00 local time during the summer). These sounding atmospheric profiles (website: atmospheric sounding) served two purposes: first, they were used as inputs for the air parcel model; and second, they were used to calculate the LCL. The LCL itself was derived by two different methods: (1) the method used by the University of Wyoming (website: sounding station parameters and indices), which uses the average value of the lower $500 \mathrm{~m}$ of the atmosphere (referred to hereafter as the average LCL); and (2) a widely used approximation described by Bolton (1980) and Stull (1988):

$$
\begin{aligned}
& T_{\mathrm{LCL}}=\frac{1}{\frac{1}{T_{k}-55 \frac{\ln \left(\frac{\mathrm{RH}}{100}\right)}{2840}}+55,} \\
& P_{\mathrm{LCL}}=P\left(\frac{T_{\mathrm{LCL}}}{T_{k}}\right)^{3.5},
\end{aligned}
$$

where $T_{k}, P$ and RH are the temperature, pressure and relative humidity, respectively, of the air parcel at the ground level (referred to hereafter as the ground LCL). 
Appendix B: The atmospheric profile used in this study

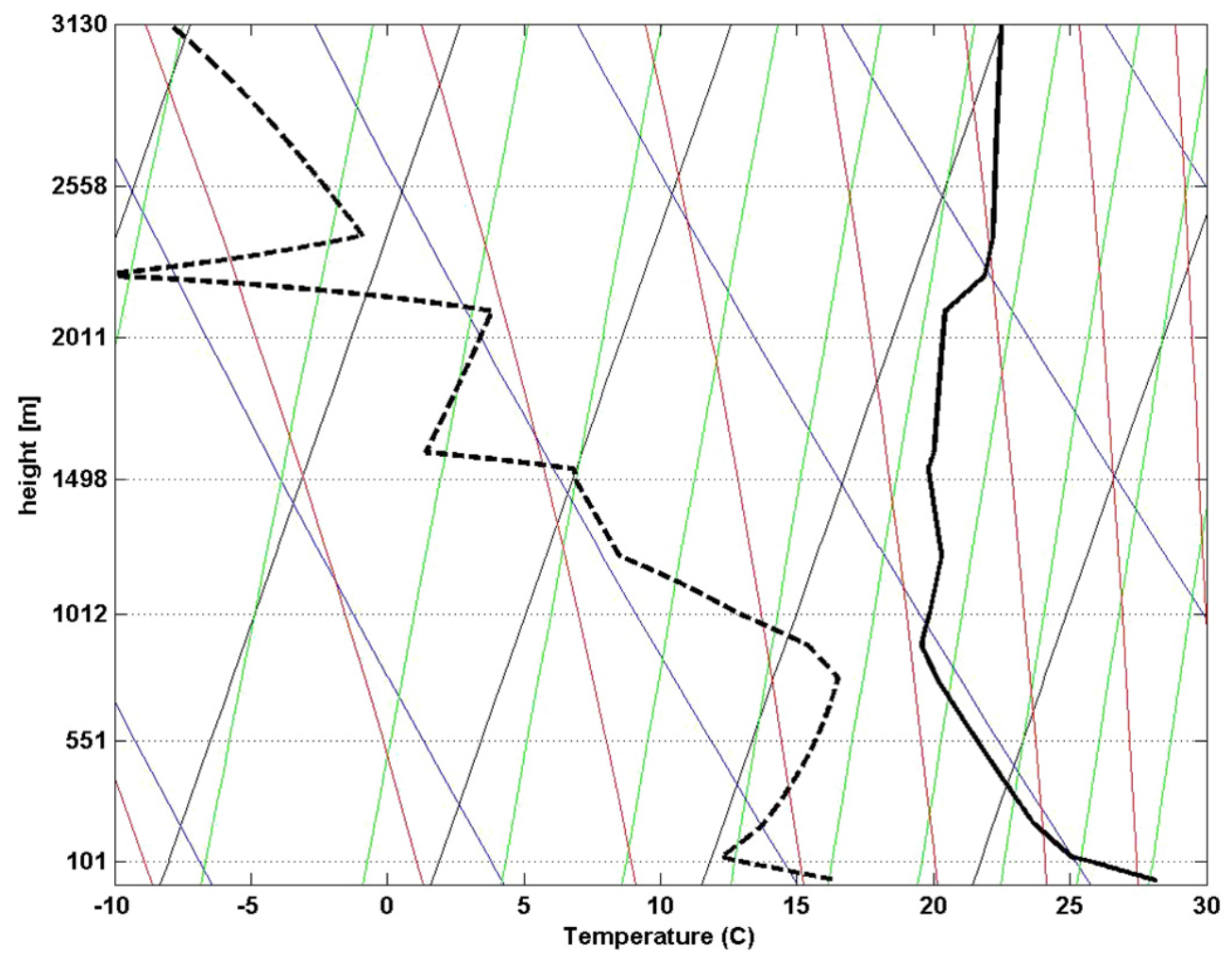

Figure B1. Tephigram of the atmospheric profile used in the model. 
Acknowledgements. The research leading to these results was funded by the European Research Council under the European Union's Seventh Framework Programme (FP7/2007-2013)/ERC grant agreement no. 306965 .

Edited by: B. Vogel

\section{References}

Asmi, A., Wiedensohler, A., Laj, P., Fjaeraa, A.-M., Sellegri, K., Birmili, W., Weingartner, E., Baltensperger, U., Zdimal, V., Zikova, N., Putaud, J.-P., Marinoni, A., Tunved, P., Hansson, H.C., Fiebig, M., Kivekäs, N., Lihavainen, H., Asmi, E., Ulevicius, V., Aalto, P. P., Swietlicki, E., Kristensson, A., Mihalopoulos, N., Kalivitis, N., Kalapov, I., Kiss, G., de Leeuw, G., Henzing, B., Harrison, R. M., Beddows, D., O'Dowd, C., Jennings, S. G., Flentje, H., Weinhold, K., Meinhardt, F., Ries, L., and Kulmala, M.: Number size distributions and seasonality of submicron particles in Europe 2008-2009, Atmos. Chem. Phys., 11, 5505-5538, doi:10.5194/acp-11-5505-2011, 2011.

Atmospheric sounding: http://weather.uwyo.edu/upperair/ sounding.html, last access: October 2013.

Berg, L. K. and Stull, R. B.: Parameterization of Joint Frequency Distributions of Potential Temperature and Water Vapor Mixing Ratio in the Daytime Convective Boundary Layer, J. Atmos. Sci., 61, 813-828, doi:10.1175/15200469(2004)061<0813:POJFDO>2.0.CO;2, 2004.

Bolton, D.: The Computation of Equivalent Potential Temperature, Mon. Weather Rev., 108, 1046-1053, 10.1175/15200493(1980)108<1046:tcoept>2.0.co;2, 1980.

Brooks, S. D., Wise, M. E., Cushing, M., and Tolbert, M. A.: Deliquescence behavior of organic/ammonium sulfate aerosol, Geophys. Res. Lett., 29, 1917, doi:10.1029/2002GL014733, 2002.

Charlson, R. J., Ackerman, A. S., Bender, F. A. M., Anderson, T. L., and Liu, Z.: On the climate forcing consequences of the albedo continuum between cloudy and clear air, Tellus B, 59, 715-727, 2007

Deng, Z., Zhao, C., Zhang, Q., Huang, M., and Ma, X.: Statistical analysis of microphysical properties and the parameterization of effective radius of warm clouds in Beijing area, Atmos. Res., 93, 888-896, 2009.

Dusek, U., Frank, G., Hildebrandt, L., Curtius, J., Schneider, J., Walter, S., Chand, D., Drewnick, F., Hings, S., and Jung, D.: Size matters more than chemistry for cloud-nucleating ability of aerosol particles, Science, 312, 1375-1378, 2006.

Han, Q., Rossow, W. B., and Lacis, A. A.: Near-global survey of effective droplet radii in liquid water clouds using ISCCP data, J. Climate, 7, 465-497, 1994.

Han, Q., Welch, R., Chou, J., Rossow, W., and White, A.: Validation of satellite retrievals of cloud microphysics and liquid water path using observations from FIRE, J. Atmos. Sci., 52, 4183-4195, 1995.

Hirsch, E., Agassi, E., and Koren, I.: Determination of optical and microphysical properties of thin warm clouds using ground based hyper-spectral analysis, Atmos. Meas. Tech., 5, 851-871, doi:10.5194/amt-5-851-2012, 2012.

Kawamoto, K., Nakajima, T., and Nakajima, T. Y.: A global determination of cloud microphysics with AVHRR remote sensing, J. Climate, 14, 2054-2068, 2001.
Köhler, H.: The nucleus in and the growth of hygroscopic droplets, T. Faraday Soc., 32, 1152-1161, 1936.

Komppula, M., Lihavainen, H., Kerminen, V. M., Kulmala, M., and Viisanen, Y.: Measurements of cloud droplet activation of aerosol particles at a clean subarctic background site, J. Geophys. Res.Atmos., 110, D06204, doi:10.1029/2004JD005200, 2005.

Koren, I., Remer, L. A., Kaufman, Y. J., Rudich, Y., and Martins, J. V.: On the twilight zone between clouds and aerosols, Geophys. Res. Lett., 34, L08805, doi:10.1029/2007GL029253, 2007.

Koren, I., Oreopoulos, L., Feingold, G., Remer, L. A., and Altaratz, O.: How small is a small cloud?, Atmos. Chem. Phys., 8, 38553864, doi:10.5194/acp-8-3855-2008, 2008.

Lee, I.-Y., and Pruppacher, H.: A comparative study on the growth of cloud drops by condensation using an air parcel model with and without entrainment, Pure Appl. Geophys., 115, 523-545, 1977.

Liu, G., Shao, H., Coakley, J. A., Curry, J. A., Haggerty, J. A., and Tschudi, M. A.: Retrieval of cloud droplet size from visible and microwave radiometric measurements during INDOEX: Implication to aerosols' indirect radiative effect, J. Geophys. Res.Atmos., 108, 4006, doi:10.1029/2001JD001395, 2003.

Mason, B. and Chien, C.: Cloud-droplet growth by condensation in cumulus, Q. J. Roy. Meteorol. Soc., 88, 136-142, 1962.

Miles, N. L., Verlinde, J., and Clothiaux, E. E.: Cloud droplet size distributions in low-level stratiform clouds, J. Atmos. Sci., 57 , 295-311, 2000.

Mordy, W.: Computations of the growth by condensation of a population of cloud droplets, Tellus, 11, 16-44, 1959.

Pruppacher, H. R. and Klett, J. D.: Microphysics of clouds and precipitation, Springer, 1998.

Reid, J. S., Hobbs, P. V., Rangno, A. L., and Hegg, D. A.: Relationships between cloud droplet effective radius, liquid water content, and droplet concentration for warm clouds in Brazil embedded in biomass smoke, J. Geophys. Res.-Atmos., 104, 61456153, 1999.

Reutter, P., Su, H., Trentmann, J., Simmel, M., Rose, D., Gunthe, S. S., Wernli, H., Andreae, M. O., and Pöschl, U.: Aerosol- and updraft-limited regimes of cloud droplet formation: influence of particle number, size and hygroscopicity on the activation of cloud condensation nuclei (CCN), Atmos. Chem. Phys., 9, 70677080, doi:10.5194/acp-9-7067-2009, 2009.

Rogers, R.: A short course in cloud physics, Oxford and Elmsford, N. Y., Pergamon Press, International Series in Natural Philosophy, 96, 246, 1979.

Rose, D., Gunthe, S. S., Mikhailov, E., Frank, G. P., Dusek, U., Andreae, M. O., and Pöschl, U.: Calibration and measurement uncertainties of a continuous-flow cloud condensation nuclei counter (DMT-CCNC): CCN activation of ammonium sulfate and sodium chloride aerosol particles in theory and experiment, Atmos. Chem. Phys., 8, 1153-1179, doi:10.5194/acp-8-11532008, 2008.

Snider, J. R., Guibert, S., Brenguier, J.-L., and Putaud, J.-P.: Aerosol activation in marine stratocumulus clouds: 2 . Köhler and parcel theory closure studies, J. Geophys. Res.-Atmos., 108, 8629, doi:10.1029/2002JD002692, 2003.

Vogelmann, A. M., McFarquhar, G. M., Ogren, J. A., Turner, D. D., Comstock, J. M., Feingold, G., Long, C. N., Jonsson, H. H., Bucholtz, A., and Collins, D. R.: RACORO extended-term aircraft 
observations of boundary layer clouds, B. Am. Meteorol. Soc., 93, 861-878, 2012.

Wallace, J. M. and Hobbs, P. V.: Atmospheric science: an introductory survey, Academic Press, 2006.
Wood, R., and Field, P. R.: The distribution of cloud horizontal sizes, J. Climate, 24, 4800-4816, 2011.

Zhao, G. and Di Girolamo, L.: Statistics on the macrophysical properties of trade wind cumuli over the tropical western Atlantic, J. Geophys. Res.-Atmos., 112, D10204, doi:10.1029/2006JD007371, 2007. 